\title{
Electrochemical oxidation of trace organic contaminants in reverse osmosis concentrate using $\mathrm{RuO}_{2} / \mathrm{IrO}_{2}$-coated titanium anodes
}

\author{
Jelena Radjenovic*, Arseto Bagastyo, René A. Rozendal, Yang Mu, Jürg Keller, \\ Korneel Rabaey
}

Advanced Water Management Centre, The University of Queensland, Brisbane, QLD 4072, Australia

\section{A R T I C L E I N F O}

Article history:

Received 26 July 2010

Received in revised form

24 November 2010

Accepted 24 November 2010

Available online 1 December 2010

Keywords:

Water recycling

Reverse osmosis

Advanced oxidation

Pharmaceuticals

Pesticides

LC-MS

Microtox test

\begin{abstract}
A B S T R A C T
During membrane treatment of secondary effluent from wastewater treatment plants, a reverse osmosis concentrate (ROC) containing trace organic contaminants is generated. As the latter are of concern, effective and economic treatment methods are required. Here, we investigated electrochemical oxidation of $\mathrm{ROC}$ using $\mathrm{Ti} / \mathrm{Ru}_{0.7} \mathrm{Ir}_{0.3} \mathrm{O}_{2}$ electrodes, focussing on the removal of dissolved organic carbon (DOC), specific ultra-violet absorbance at $254 \mathrm{~nm}\left(\mathrm{SUVA}_{254}\right)$, and 28 pharmaceuticals and pesticides frequently encountered in secondary treated effluents. The experiments were conducted in a continuously fed reactor at current densities $(J)$ ranging from 1 to $250 \mathrm{~A} \mathrm{~m}^{-2}$ anode, and a batch reactor at $J=250 \mathrm{~A} \mathrm{~m}^{-2}$. Higher mineralization efficiency was observed during batch oxidation (e.g. $25.1 \pm 2.7 \%$ DOC removal vs $0 \%$ removal in the continuous reactor after applying specific electrical charge, $\mathrm{Q}=437.0 \mathrm{~A} \mathrm{~h} \mathrm{~m}^{-3} \mathrm{ROC}$ ), indicating that DOC removal is depending on indirect oxidation by electrogenerated oxidants that accumulate in the bulk liquid. An initial increase and subsequent slow decrease in $\mathrm{SUVA}_{254}$ during batch mode suggests the introduction of auxochrome substituents (e.g. $-\mathrm{Cl}, \mathrm{NH}_{2} \mathrm{Cl},-\mathrm{Br}$, and $-\mathrm{OH}$ ) into the aromatic compounds. Contrarily, in the continuous reactor ring-cleaving oxidation products were generated, and $\mathrm{SUVA}_{254}$ removal correlated with applied charge. Furthermore, 20 of the target pharmaceuticals and pesticides completely disappeared in both the continuous and batch experiments when applying $\mathrm{J} \geq 150 \mathrm{~A} \mathrm{~m}^{-2}$ (i.e. $\mathrm{Q} \geq 461.5 \mathrm{~A} \mathrm{~h} \mathrm{~m}^{-3}$ ) and $437.0 \mathrm{~A} \mathrm{~h} \mathrm{~m}^{-3}$ $\left(J=250 \mathrm{~A} \mathrm{~m}^{-2}\right)$, respectively. Compounds that were more persistent during continuous oxidation were characterized by the presence of electrophilic groups on the aromatic ring (e.g. triclopyr) or by the absence of stronger nucleophilic substituents (e.g. ibuprofen). These pollutants were oxidized when applying higher specific electrical charge in batch mode (i.e. $1.45 \mathrm{kA} \mathrm{h} \mathrm{m}^{-3} \mathrm{ROC}$ ). However, baseline toxicity as determined by Vibrio fischeri bioluminescence inhibition tests (Microtox) was increasing with higher applied charge during batch and continuous oxidation, indicating the formation of toxic oxidation products, possibly chlorinated and brominated organic compounds.
\end{abstract}

(c) 2010 Elsevier Ltd. All rights reserved.

\footnotetext{
* Corresponding author. Tel.: +61 73346 3234; fax: +61 733654726.

E-mail address: j.radjenovic@awmc.uq.edu.au (J. Radjenovic). 


\section{Introduction}

Due to the growing pressure on water resources, the use of treated municipal wastewater for groundwater recharge and indirect potable reuse is increasingly considered. A number of reuse facilities worldwide currently employ microfiltration (MF) followed by reverse osmosis (RO) for the treatment of secondary treated effluent prior to aquifer or reservoir recharge. High-pressure RO membranes have gained popularity due to their outstanding performance in rejecting trace organics such as endocrine disrupting compounds, pesticides, pharmaceuticals and others (Bellona and Drewes, 2007; Radjenovic et al., 2008; Snyder et al., 2007). These compounds will be concentrated four to seven times in the waste stream (reverse osmosis concentrate, ROC) that normally comprises about $15-25 \%$ of the incoming water flow. The ROC offers an opportunity for reducing human and ecotoxicological risk by implementing brine treatment prior to environmental discharge.

Several advanced oxidation treatment options (e.g. $\mathrm{TiO}_{2}$ photocatalysis, sonolysis) showed moderate performance in removing the organic matter from ROC (Dialynas et al., 2008; Westerhoff et al., 2009). In the past years, electrochemical oxidation processes received renewed interest due to several perceived advantages such as efficient control of reaction conditions, no chemical requirements, simplicity and robustness of operation at ambient temperature and pressure. Van Hege and co-workers pioneered the electrochemical oxidation of ROC (Van Hege et al., 2002). More recent work by Dialynas et al. (2008) reported moderate dissolved organic carbon (DOC) removal in electrolytic oxidation of ROC on boron-doped diamond (BDD) anodes, while Perez et al. (2010) observed an excellent performance by BDD in eliminating chemical oxygen demand (COD) and 10 pharmaceuticals and stimulant drugs from ROC.

Due to recent advances in electrode stability and performance, electrochemically driven processes are becoming an attractive option for the remediation of problematic waste streams. Notably, mixed metal oxide (MMO) coated electrodes have found widespread environmental applications in recent years for the treatment of pesticide contaminated water, landfill leachate, organic petroleum wastewater and other difficult to treat waste streams (Panizza, 2010). MMO anodes such as $\mathrm{RuO}_{2} / \mathrm{IrO}_{2}$-coated titanium with improved electrocatalytic behaviour and stability are readily available in practical mesh geometries and have extended life-time and lower costs relative to BDD electrodes. The latter have thus far been considered as the standard for electrochemical oxidation, but suffer from high product costs. Because of their low overpotential for chlorine evolution, $\mathrm{RuO}_{2} / \mathrm{IrO}_{2}$-coated electrodes were effectively used for the degradation of pharmaceuticals, pesticides and other organic compounds via indirect electrolysis (Malpass et al., 2006; Carlesi Jara et al., 2007; Gallard et al., 2004). However, while on one hand in-situ generated active chlorine can effectively oxidize many pollutants, on the other hand the formation of chlorinated byproducts could lead to increased toxicity levels. Different operational strategies were proposed in literature for minimizing the formation of chlorinated organic compounds, such as application of long residence time and activated carbon polishing treatment (Rajkumar et al., 2005), continuous operation and short residence time (Bergmann and Koparal, 2005a), and over saturation of the solution by chlorine. The latter approach increases the degradation rate of chlorinated intermediates relative to their rate of formation (Gallard et al., 2004).

In this study, the electrochemical oxidation using $\mathrm{Ti} /$ $\mathrm{Ru}_{0.7} \mathrm{Ir}_{0.3} \mathrm{O}_{2}$ electrode was investigated for the treatment of ROC. The process efficiency was evaluated based on the removal of DOC, specific ultra-violet absorbance at $254 \mathrm{~nm}$ $\left(\mathrm{SUVA}_{254}\right)$, and 28 pesticides and pharmaceuticals encompassing diverse molecular structures and physico-chemical properties (Table S1), selected for their ubiquity in municipal wastewater effluents and brine streams. The influence of operational mode, current density, and applied electrical charge on the oxidation efficiency was investigated. The baseline toxicity of electrochemically oxidized ROC was evaluated in the bioluminescence inhibition tests (Microtox) using the marine bacterium Vibrio fischeri.

\section{Materials and methods}

\subsection{Chemicals}

All standards for pharmaceuticals and pesticides used were of analytical grade ( $\geq 99 \%$ ) (Text $\mathrm{S} 1$ ). All solvents (methanol, acetonitrile and water) were HPLC-grade and were purchased from Merck (Germany), as well as hydrochloric acid (37\%), ammonium acetate, sodium hydroxide and formic acid (98\%).

\subsection{Reverse osmosis concentrate}

The ROC used in the experiments was sampled at an advanced water treatment plant (AWTP) in Bundamba, $30 \mathrm{~km}$ west of Brisbane, Australia. This AWTP receives a mixture of secondary treated effluents from four wastewater treatment plants. After the pre-treatment of secondary effluents (addition of iron coagulants, separation of solids in the clarifier), raw water is passed through MF and RO membranes. The generated ROC is further subjected to nitrification in a moving bed biofilm reactor (MBBR), coagulation and denitrification by anoxic filters, and is finally discharged into the Brisbane River. In order to investigate the removal of trace organic contaminants during electrochemical oxidation, ROC collected prior to the nitrification stage was spiked with the concentrated solutions of target compounds prepared in water and methanol. The spiking solution of compounds soluble in water was prepared from pure standards at $\sim 1 \mathrm{mg} \mathrm{L}^{-1}$ concentration, and for each $10 \mathrm{~L}$ of ROC, $100 \mathrm{~mL}$ of spiking solution in water was added. The spiking solution of compounds poorly soluble in water was prepared in methanol at $1 \mathrm{~g} \mathrm{~L}^{-1}$ concentration, and for each $10 \mathrm{~L}$ of ROC, $100 \mu \mathrm{L}$ of spiking solution in methanol was added. Since methanol can act as a scavenger of the generated oxidants, the amount added was minimized. In order to ensure homogeneity, the spiked ROC sample was filtered through $0.7 \mu \mathrm{m}$ glass fibre filters (Whatman, UK) prior to the experiments. The obtained final concentrations of 
target analytes were in the range of 7.8 (carbamazepine) to $37.4 \mu \mathrm{g} \mathrm{L}^{-1}$ (iopromide) (Table S2).

\subsection{Experimental setup}

The electrochemical cell was constructed by assembling two equal rectangular polycarbonate frames with internal dimensions of $20 \times 5 \times 1.2 \mathrm{~cm}$. The frames were bolted together between two polycarbonate square plates. The anode cell was separated from the cathode cell by a cation exchange membrane Ultrex CMI-7000 (Membranes International, U.S.A.). Sealing was ensured by a rubber o-ring inserted between the two frames. The total volume for each compartment was $114 \mathrm{~mL}$. The anode used was an MMO Ti/ $\mathrm{Ru}_{0.7} \mathrm{Ir}_{0.3} \mathrm{O}_{2}$ electrode with $12 \mathrm{~g} \mathrm{~m}^{-2}$ coating on $\mathrm{Ti}$ mesh (dimensions: $4.8 \times 5 \mathrm{~cm}$; thickness: $1 \mathrm{~mm}$; specific surface area: $1.0 \mathrm{~m}^{2} \mathrm{~m}^{-2}$ ), supplied by Magneto Special Anodes (The Netherlands). The cathode used was a stainless steel woven wire mesh (dimensions: $4.8 \times 5 \mathrm{~cm} ; 80 \mu \mathrm{m} \times 0.050 \mathrm{~mm}$ wire diameter), and both the anode and cathode had a projected electrode surface area of $24 \mathrm{~cm}^{2}$. For electrochemical control, a Wenking potentiostat/galvanostat (KP07, Bank Elektronik, $\mathrm{GmbH}$, Pohlheim, Germany) was used. The anodic half-cell potentials were measured by placing an $\mathrm{Ag} / \mathrm{AgCl}$ reference electrode (assumed $+0.197 \mathrm{~V}$ vs SHE) in the anode compartment. The cathode medium in was a $0.1 \mathrm{M} \mathrm{HCl}$ solution.

The experiments were performed at constant liquid flowrate at room temperature $\left(25 \pm 1^{\circ} \mathrm{C}\right)$, with galvanostatic control in: i) continuous mode, with step-wise increase in current density $(J)(J=1,10,30,50,100,150,200$ and $250 \mathrm{~A} \mathrm{~m}^{-2}$ ), and samples taken after $75 \mathrm{~min}$ of operation at each current density, and ii) batch mode at $J=250 \mathrm{~A} \mathrm{~m}^{-2}$, and samples taken after 2, 4, 7 and $23.5 \mathrm{~h}$. In the continuous mode experiments, the system was operated at a hydraulic retention time (HRT) of $8.8 \mathrm{~min}$ (i.e. flow-rate of $13 \mathrm{~mL} \mathrm{~min}^{-1}$ ). In order to maintain well-mixed conditions and avoid concentration gradients, both anolyte and catholyte were recirculated internally at a rate of $162 \mathrm{~mL} \mathrm{~min}^{-1}$. In order to avoid gas trapping inside the anodic and cathodic compartment and enable stable potentials and ambient pressure, two degassers were installed as illustrated in Figure S1. The volume of ROC in the degassers was maintained at $100 \mathrm{~mL}$, providing a ratio of active and total volume, $\mathrm{V}_{\mathrm{ACT}} / \mathrm{V}_{\text {TOT }}$ of 0.51 in the continuous mode. Preparative continuous oxidation experiments were carried out in order to establish the time required to reach steady state. In the batch mode experiments, anolyte and catholyte were recirculated at a rate of $162 \mathrm{~mL} \mathrm{~min}^{-1}$. The volume of ROC used in batch experiments was $10 \mathrm{~L}$, hence the ratio of $\mathrm{V}_{\mathrm{ACT}} / \mathrm{V}_{\text {TOT }}$ was 0.011 . The results of each experimental condition are given as the means of triplicates, with their corresponding standard deviations (SDs). In the continuous experiments two different ROC samples were used, collected at the abovementioned AWTP within a one month time span and marked as ROC-1 and ROC-2 (physico-chemical characteristics of ROC-1 and ROC-2 are given in Table 1), while in batch experiments only ROC-1 was used.

\subsection{Analytical methods}

$130 \mathrm{~mL}$ samples were collected in amber glass bottles. As a variety of generated oxidants can prevent efficient sample stabilization, no quenching agent was added to the sample. Furthermore, quenching of free chlorine may lead to errors in analytical determination of trace organics due to the formation of the original compounds from their N-chloro analogues (Wulfeck-Kleier et al., 2010). Immediately after the sampling, sample $\mathrm{pH}$ was adjusted to $\mathrm{pH} 7.0$ by adding an appropriate amount of $0.1 \mathrm{M} \mathrm{NaOH}$ or $0.1 \mathrm{M} \mathrm{HCl}$, and $100 \mathrm{~mL}$ samples were extracted on a Visiprep manifold system (Sigma-Aldrich, U.S.A.) using Oasis HLB cartridges $(200 \mathrm{mg}, 6 \mathrm{~mL})$ from Waters Corporation (U.S.A.), previously conditioned with $10 \mathrm{~mL}$ of methanol and $10 \mathrm{~mL}$ of deionised water (HPLC grade). Additionally, $30 \mathrm{~mL}$ samples were taken for the analyses of free and combined chlorine, non-purgeable organic carbon (NPOC) and ultra-violet absorption at $254 \mathrm{~nm}\left(\mathrm{UV}_{254}\right)$.

The samples were filtered prior to all measurements using $0.45 \mu \mathrm{m}$ filters (Millipore, Ireland), thus the determined NPOC is equivalent to DOC. NPOC was calculated as the difference between the total carbon (TC) and inorganic carbon that were determined by the standard high-temperature method (APHA Standard methods, 5310B) at a TC analyser (Tekmar Dohrmann DC-190), and $\mathrm{UV}_{254}$ absorbance was measured using a Varian Cary50 spectrophotometer. Ion chromatography (IC)Dionex $2010 \mathrm{i}$ was used to determine $\mathrm{Cl}^{-}$and $\mathrm{SO}_{4}^{2-}$, while concentrations of $\mathrm{Fe}^{2+}$ and $\mathrm{Mn}^{2+}$ ions were determined by ICPOES Vista Pro-CCD (Varian, Australia). Conductivity was measured using a Eutech electrical conductivity meter, while the $\mathrm{pH}$ was measured with a Mettler Toledo Seven easy $\mathrm{pH}$ meter (Mettler Toledo, Australia). Free available chlorine (FAC) and total chlorine were measured with the N,N-diethyl-pphenylenediamine (DPD) ferrous titrimetric method (APHA Standard methods, 409E). It is important to stress that oxidants other than FAC present in the solution (e.g. $\mathrm{H}_{2} \mathrm{O}_{2}$, $\mathrm{ClO}_{2}$ ) will similarly to chlorine react with DPD to form a red dye, thus interfering with the measurements.

Liquid chromatography-mass spectrometry (LC-MS) analyses were performed using a Shimadzu Prominence ultra-fast liquid chromatography (UFLC) system (Shimadzu, Japan) coupled with a 4000 QTRAP hybrid triple quadrupole-linear ion trap mass spectrometer (QqLIT-MS) equipped with a Turbo Ion Spray source (Applied Biosystems-Sciex, U.S.A.). Chromatographic separation was achieved with an Alltima C18

\begin{tabular}{|c|c|c|c|c|c|c|c|c|}
\hline & $\begin{array}{l}\text { DOC, } \\
\mathrm{mg} \mathrm{L}^{-1}\end{array}$ & $\begin{array}{l}\text { SUVA254, } \\
\mathrm{L} \mathrm{mg}^{-1} \mathrm{~m}^{-1}\end{array}$ & $\begin{array}{l}\text { Conductivity, } \\
\mathrm{mS} \mathrm{cm}^{-1}\end{array}$ & $\mathrm{pH}$ & $\begin{array}{l}{\left[\mathrm{Fe}^{2+}\right]} \\
\mathrm{mg} \mathrm{L}^{-1}\end{array}$ & $\begin{array}{l}\left.\mathrm{Mn}^{2+}\right] \\
\mu \mathrm{g} \mathrm{L}^{-1}\end{array}$ & $\begin{array}{l}{\left[\mathrm{Cl}^{-}\right]} \\
\mathrm{g} \mathrm{L}^{-1}\end{array}$ & $\begin{array}{l}{\left[\mathrm{SO}_{4}^{2-}\right]} \\
\mathrm{mg} \mathrm{L}^{-1}\end{array}$ \\
\hline ROC-1 & 57.1 & 1.6 & 4.25 & 7.5 & 0.22 & 227 & 1.5 & 241.5 \\
\hline ROC-2 & 57.2 & 2.3 & 3.97 & 7.7 & 0.35 & 234 & 1.2 & 238.7 \\
\hline
\end{tabular}


Column $(250 \times 4.6 \mathrm{~mm}$, particle size $5 \mu \mathrm{m})$ run at $40{ }^{\circ} \mathrm{C}$, supplied by Alltech Associates Inc (U.S.A.). The multi-residue method used is described in the Text S2, and Tables S3 and S4. The recoveries and method quantification limits (MQLs) are summarized in Table S2.

\subsection{Microtox bioassays}

For the V. fischeri bioassays, ROC-1 spiked with the mixture of target analytes was electrochemically oxidized in continuous mode with a step-wise increase in current density (i.e., $J=50$, $100,150,200$ and $250 \mathrm{~A} \mathrm{~m}^{-2}$ ), and in batch mode at $J=250 \mathrm{~A} \mathrm{~m}^{-2}$. Sampling times and sample pre-treatment were identical to the ones described in the sections Experimental setup and Analytical methods, respectively. The results of the acute toxicity tests are expressed in baseline-toxic equivalent concentration (TEQ) units, derived from a baseline toxicity quantitative structure-activity relationship (QSAR) model using a virtual compound with octanol-water partition coefficient (log $\mathrm{K}_{\mathrm{OW}}$ ) of 3 and molecular weight (MW) of $300 \mathrm{~g} \mathrm{~mol}^{-1}$ as a reference, which equates to an $\mathrm{EC}_{50}$ of $12 \mathrm{mg} \mathrm{L}^{-1}$ (Escher et al., 2008).

\section{Results and discussion}

3.1. Electrochemical oxidation - overall organics removal in batch and continuous mode

Fig. 1 illustrates the observed removal of DOC and SUVA 254 , and measured free and total chlorine during continuous oxidation of ROC-1 and ROC-2. There was no DOC removal for

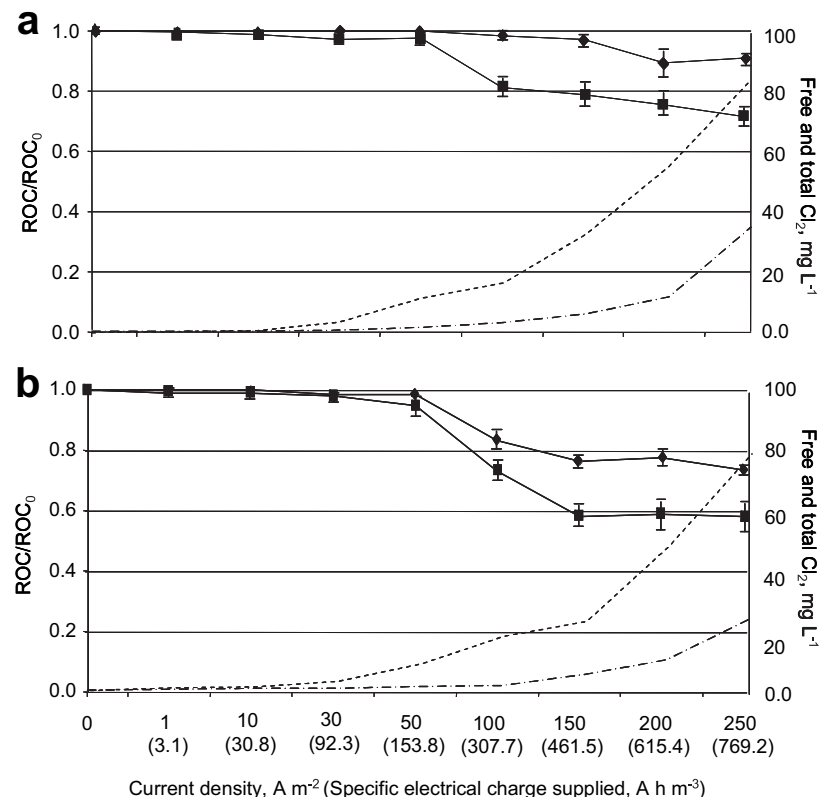

Fig. 1 - Removal of DOC, SUVA 254 and generation of free and total chlorine during anodic oxidation in continuous mode of: a) ROC-1 and b) ROC-2 spiked with the trace organic contaminants, vs $\mathrm{J}$ (in $\mathrm{A} \mathrm{m}^{-2}$ ) and $\mathrm{Q}$ (in $\mathrm{A} \mathrm{h} \mathrm{m}^{-3}$ ). $\diamond \mathrm{DOC} \mathrm{DOC}_{0}, \mathbf{}_{\mathrm{SUVA}}{ }_{254} /\left(\mathrm{SUVA}_{254}\right)_{0}$, - - - free chlorine, total chlorine. low specific electrical charges $\left(\mathrm{Q}_{\mathrm{sp}}\right.$, expressed as $\left.\mathrm{A} \mathrm{h} \mathrm{m}^{-3} \mathrm{ROC}\right)$ applied $\left(\mathrm{Q}_{\mathrm{sp}} \leq 307.7\right.$ and $153.8 \mathrm{~A} \mathrm{~h} \mathrm{~m}^{-3}$ for ROC-1 and ROC-2, respectively), while $\mathrm{SUVA}_{254}$ was relatively constant at $\mathrm{Q}_{\mathrm{sp}} \leq 153.8 \mathrm{~A} \mathrm{~h} \mathrm{~m}^{-3}$ for both ROCs tested. By increasing the applied charge, a gradual decrease in DOC was observed, reaching $8.9 \pm 1.4$ and $26.5 \pm 2.3 \%$ removal after $769.2 \mathrm{~A} \mathrm{~h} \mathrm{~m}^{-3}$ supplied to ROC-1 and ROC-2, respectively. Considering that the initial chloride ion concentrations as well as residual chlorine concentrations measured for the ROC-1 and ROC-2 were similar, more efficient mineralization in the latter case is possibly a consequence of the higher initial specific aromaticity of ROC- 2 as expressed by its SUVA $_{254}$ value (Table 1). The enhanced formation of putative electron shuttles (e.g. porphyrins, quinones) from the aromatic fraction could be responsible for the higher NPOC removal observed for ROC-2, as these species accelerate the electron transfer between the organic matter and oxidants (Nurmi and Tratnyek, 2002). The removal of $\mathrm{SUVA}_{254}$ was also enhanced with increasing the supplied charge, and $28.7 \pm 1.8 \%$ and $42 \pm 2.4 \%$ removal was observed after applying 769.2 $\mathrm{A} \mathrm{h} \mathrm{m}^{-3}$ to ROC-1 and ROC-2, respectively.

The DOC removal achieved in batch oxidation of ROC-1 was $30.7 \pm 1.8 \%$ after passing $1.45 \mathrm{kA} \mathrm{h} \mathrm{m}^{-3}$ (Fig. 2). When comparing the oxidation of ROC- 1 in the two operational modes tested, the same values of $\mathrm{Q}_{\mathrm{sp}}\left(\sim 770 \mathrm{Ah} \mathrm{m}^{-3}\right)$ and $J\left(250 \mathrm{~A} \mathrm{~m}^{-2}\right)$ in batch and continuous and oxidation of ROC-1 rendered DOC removal of $\sim 27$ and $8.9 \pm 1.4 \%$, and $\mathrm{SUVA}_{254}$ was $\geq 1$ and 0.71 (i.e. $28.7 \pm 1.8 \%$ of SUVA $_{254}$ removal), respectively (Figs. 1 and 2). Thus, the removal of organic carbon depended on the accumulation of long lived oxidants (e.g. $\mathrm{HClO} / \mathrm{ClO}^{-}, \mathrm{HOBr}$ and $\mathrm{H}_{2} \mathrm{O}_{2}$ ) in the bulk liquid. For the final DOC removal achieved in continuous $(8.9 \pm 1.4 \%)$ and batch mode $(30.7 \pm 1.8 \%)$ oxidation of ROC-1 at $250 \mathrm{~A} \mathrm{~m}^{-2}$, energy consumption calculated according to Bolton et al. (2001) was $0.704 \mathrm{kWh} \mathrm{g}_{\mathrm{DOC}}^{-1}$ and $0.350 \mathrm{kWh} \mathrm{g}_{\mathrm{DOC}}^{-1}$, respectively. Thus, more efficient removal of organic matter is achieved in batch mode, and the energy input per mass unit of DOC removed is lower compared to the continuously operated reactor. Nevertheless, lower throughput of batch mode compared to a continuous mode may increase significantly the total cost of the treatment.

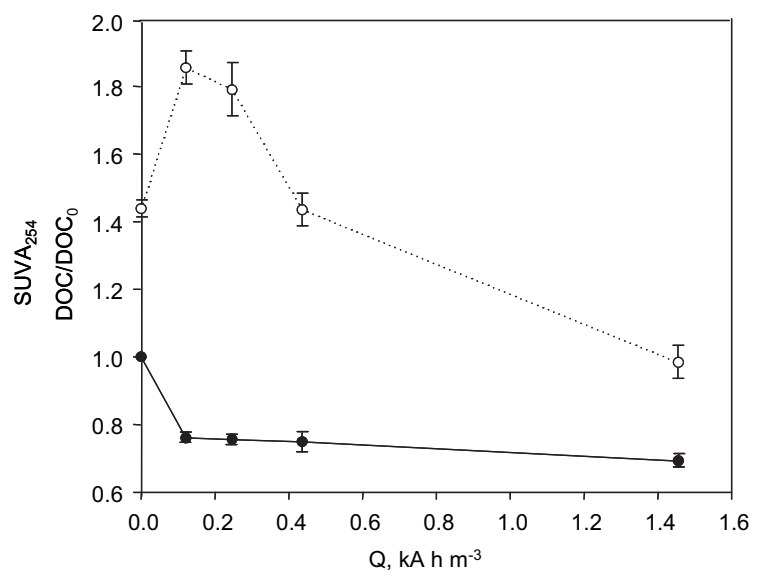

Fig. 2 - DOC removal and SUVA 254 vs $Q$ in anodic oxidation in batch mode at $574 \mathrm{~J}=250 \mathrm{~A} \mathrm{~m}^{-2}$ of ROC-1 spiked with the trace organic contaminants. ... O $\cdots$ SUVA $_{254}, \longrightarrow-\mathrm{DOC} /$ DOC $_{0}$. 
The decrease in $\mathrm{SUVA}_{254}$ and the limited DOC removal observed in the continuous experiments suggested that organic intermediates were mainly generated by oxidative cleavage and opening of the aromatic moieties. On the other hand, introduction of auxochrome substituents (e.g. $-\mathrm{Cl}$, $\left.\mathrm{NH}_{2} \mathrm{Cl},-\mathrm{Br},-\mathrm{OH}\right)$ into the aromatic rings during batch oxidation led to an initial increase in $\mathrm{SUVA}_{254}$, as DOC decay was faster than the decrease in $\mathrm{UV}_{254}$ absorbance. Much higher share of active volume (i.e. ROC oxidized inside the anodic compartment) in a continuous reactor $\left(\mathrm{V}_{\mathrm{ACT}} / \mathrm{V}_{\mathrm{TOT}}=0.51\right)$ compared to the batch reactor $\left(\mathrm{V}_{\mathrm{ACT}} / \mathrm{V}_{\mathrm{TOT}}=0.011\right)$ led to enhanced reaction of organic matter with short-lived radical oxygen species (ROS) and/or radical halogen species (RHS), which are more capable of ring-opening than more stable oxidants (e.g. FAC, $\mathrm{O}_{2}, \mathrm{H}_{2} \mathrm{O}_{2}$ ). However, only partial DOC removal was achieved in both continuous and batch oxidation, indicating the accumulation of oxidation intermediates.

\subsection{Removal of trace organic contaminants in continuous mode}

Fig. 3 illustrates the removals of trace organic compounds observed in the continuous experiments conducted at higher current densities $\left(\mathrm{J}=100-250 \mathrm{~A} \mathrm{~m}^{-2}\right)$. The removals obtained at lower currents $\left(J=1-50 \mathrm{~A} \mathrm{~m}^{-2}\right)$ are represented in Figure $\mathrm{S} 2$. The term "removal" is used here for the conversion of a target analyte to compounds other than the parent compound. Since at low current densities $\left(J=1,10 \mathrm{~A} \mathrm{~m}^{-2}\right)$ the likely mechanism for oxidation of pollutants is direct electrolysis, the rate of direct oxidation depends on the adsorption properties of the anode surface, and concentration and nature of trace organic compounds and their degradation intermediates (Panizza, 2010). Except for sertraline, removed at 70\% efficiency, for most of the target analytes no removal or very low removal $(\leq 30 \%)$ was observed under these conditions (Figure S2). Considering the adsorption properties of $\mathrm{RuO}_{2} / \mathrm{IrO}_{2}$ anodes, very high removal of sertraline even at $J=1 \mathrm{~A} \mathrm{~m}^{-2}$ can be explained by its hydrophobic nature, as sertraline has the highest $\log \mathrm{K}_{\mathrm{OW}}$ value (5.29) among the selected analytes.

The increase in applied charge to 92.3 and $153.8 \mathrm{~A} \mathrm{~h} \mathrm{~m}^{-3}$ (i.e. $J=30$ and $50 \mathrm{~A} \mathrm{~m}^{-2}$ ) exerted a notable effect on the removal of acetaminophen (40\% and 90\%), diclofenac (40\% and $88 \%$ ), sulfadiazine ( $44 \%$ and $88 \%$ ), diazinon ( $40 \%$ and $70 \%$ ) and norfloxacin (65\% and 90\%), and led to a complete removal of ranitidine $(100 \%)$ and lincomycin (>90\% and $100 \%$, respectively). Bergmann and Koparal (2005a) reported an increase in $\mathrm{RuO}_{2} /$ $\mathrm{IrO}_{2}$ electrode activity anode potentials $\left(\mathrm{E}_{\mathrm{AN}}\right)$ higher than $1.3 \mathrm{~V}$, related to the production of FAC. In accordance with this study, already at $J=30 \mathrm{~A} \mathrm{~m}^{-2}$ (i.e. $E_{\mathrm{AN}}=1.32 \pm 0.05 \mathrm{~V}$, Table S5) the combined chlorine concentration of $3.0 \mathrm{mg} \mathrm{L}^{-1}$, calculated as the difference between the total and free chlorine measured (Fig. 1) implied that chlorine had already reacted to form organic and inorganic chloramines. Considering the affinity of the abovementioned compounds towards chlorine (Bedner and MacCrehan, 2006a; Westerhoff et al., 2005; Acero et al., 2008; Dodd et al., 2005), it can be assumed that they were oxidized by free chlorine. However, under the same conditions, other compounds known to have a high affinity for FAC (Bedner and MacCrehan, 2006a, 2006b; Westerhoff et al., 2005; Acero et al., 2008; Chen and Young, 2008; Chamberlain and Adams, 2006; Gould and Richards, 1984) had low removals. Examples of these are trimethoprim (25\% and $46 \%$ ), gemfibrozil (11\% and
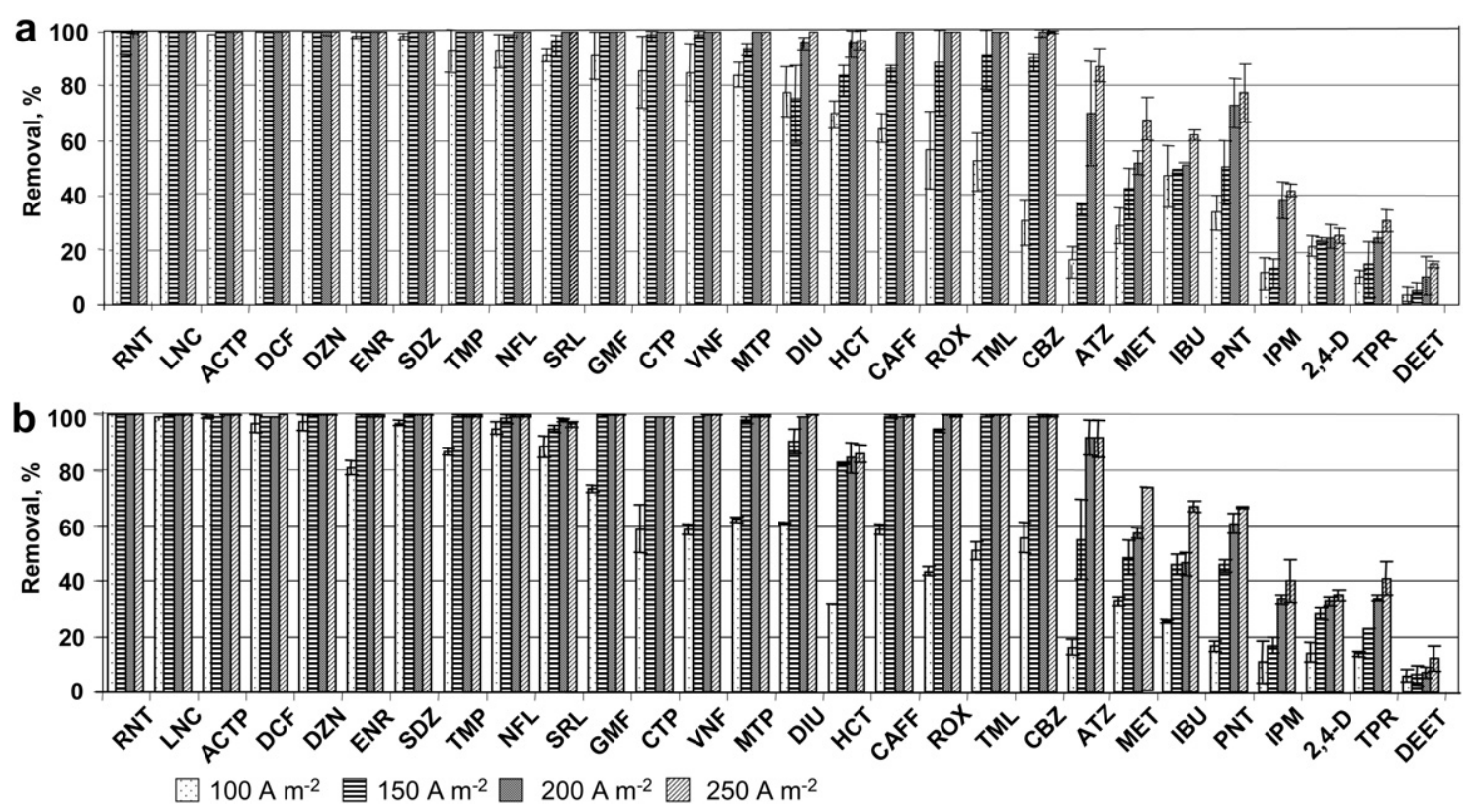

Fig. 3 - Removals of target analytes during anodic oxidation in continuous mode of: a) ROC-1 and b) ROC-2 spiked with the trace organic contaminants, for the tested $J$ in the range 100-250 $\mathrm{A} \mathrm{m}^{-2}$. RNT-ranitidine, LNC lincomycin, ACTPacetaminophen, DCF-diclofenac, DZN diazinon, ENR-enrofloxacin, SDZ-sulfadiazine, TMP-trimethoprim, NFL-norfloxacin, SRL-sertraline, GMF-gemfibrozil, CTP-citalopram, VNF-venlafaxine, MTP-metoprolol, DIU-diuron, HCT-

hydrochlorothiazide, CAFF-caffeine, ROX-roxithromycin, TML-tramadol, CBZ carbamazepine, ATZ-atrazine, METmetolachlor, IBU-ibuprofen, PNT-phenytoin, IPM-iopromide, 2,4-D-2,4-dichlorophenoxyacetic acid, TPR triclopyr. Values are expressed as mean with their SDs. 
$43 \%$ ), caffeine (14\% and $26 \%$ ), diuron (14\% and 33\%), metoprolol $(10 \%$ and $30 \%)$ at $J=30$ and $50 \mathrm{~A} \mathrm{~m}^{-2}$, respectively. Given that their initial concentrations were very similar, it appears unlikely that this would be a due to lower mass transfer coefficients. Moreover, at $J=100 \mathrm{~A} \mathrm{~m}^{-2}\left(\mathrm{E}_{\mathrm{AN}}=1.70 \pm 0.2 \mathrm{~V}\right)$ only $60 \%$ of caffeine was oxidized in both ROC-1 and ROC-2, despite its reported high reactivity with $\mathrm{FAC}$ in the $\mathrm{pH}$ range found in our experiments (e.g. 6.17 at $100 \mathrm{~A} \mathrm{~m}^{-2}$,Table S5) (Gould and Richards, 1984). At the same current density of $100 \mathrm{~A} \mathrm{~m}^{-2}$ $\left(\mathrm{Q}_{\mathrm{sp}}=307.7 \mathrm{~A} \mathrm{~h} \mathrm{~m}^{-3}\right)$, a complete disappearance of enrofloxacin was noted. Interestingly, this compound is known to react very slowly with FAC and to be recalcitrant towards $\mathrm{NH}_{2} \mathrm{Cl}$ (Dodd et al., 2005). A complete disappearance of carbamazepine from the ROC oxidized at $J=150 \mathrm{~A} \mathrm{~m}^{-2}$ was probably achieved by oxidants other than chlorine, since carbamazepine is recalcitrant even towards the much stronger oxidant $\mathrm{ClO}_{2}$ (Huber et al., 2005). The largely incomplete oxidation by FAC for some of the compounds and unexpectedly rapid disappearance of others known to react slowly with chlorine suggest that other oxidants in the bulk and/or surface reactions may play an important role. Besides reacting in the bulk, chlorine can react electrochemically at the anode forming adsorbed chloro- and oxychloro-radicals, which mediate the degradation of adsorbed organics (Bergmann and Koparal, 2005a; Papastefanakis et al., 2010). Moreover, electrogenerated $\mathrm{O}_{2}$ can indirectly oxidize the bulk organics and form organic radicals via the hydrogen abstraction mechanism (Carlesi Jara et al., 2007). Organic radicals can then further react with $\mathrm{O}_{2}$ to form organic hydroperoxides (ROOH) that are short-lived and tend to decompose, often leading to the formation of molecules with a lower number of carbon atoms. Furthermore, in the presence of $\mathrm{Fe}^{2+}$ and $\mathrm{Mn}^{2+}$ ions in ROC (Table 1) and electrogenerated $\mathrm{H}_{2} \mathrm{O}_{2}$, contribution of Fenton reaction to bulk oxidation can be expected.

Compounds that were more recalcitrant during electrochemical oxidation were characterized by either the absence of nucleophilic substituents that have an activating effect on the aromatic ring (e.g. ibuprofen, phenytoin, metolachlor, $\mathrm{N}, \mathrm{N}$-diethyl-meta-toluamide (DEET)), or by the decreased electron density on the aromatic ring due to the presence of electrophilic halogen groups (e.g. 2,4-dichlorophenoxyacetic acid (2,4-D), atrazine, triclopyr and iopromide). Further increasing the applied current density up to $250 \mathrm{~A} \mathrm{~m}^{-2}$ $\left(\mathrm{Q}_{\mathrm{sp}}=769.2 \mathrm{~A} \mathrm{~h} \mathrm{~m}^{-3}\right)$ led to an enhanced oxidation of atrazine (92\%), metolachlor (57\% and $84 \%$ ), ibuprofen (46\% and 67\%) and phenytoin (61\% and 67\%) in the ROC-1 and ROC-2, respectively. Considering the $\mathrm{E}_{\mathrm{AN}}$ (i.e. $2.5 \pm 0.07 \mathrm{~V}$ ) and the measured $\mathrm{pH}$ (i.e. $\mathrm{pH}$ 2.6, Table S5), oxidants such as $\mathrm{ClO}_{2}$, $\mathrm{HClO} / \mathrm{OCl}^{-}, \mathrm{H}_{2} \mathrm{O}_{2}$ and other radical ROS (e.g. $\mathrm{O}_{2}^{-}, \mathrm{OH}^{\bullet}, \mathrm{HO}_{2}^{*}$ ) and RHS ( $\left.\mathrm{Br}^{\mathbf{*}}, \mathrm{Br}_{2}^{\mathbf{*}}, \mathrm{Cl}^{\mathbf{*}}, \mathrm{Cl}_{2}^{--}\right)$probably had a greater participation in the indirect oxidation at this current density. Furthermore, at acidic $\mathrm{pH}$ (i.e. $\mathrm{pH} \leq 3$ ) chlorination is acidcatalysed through a mechanism involving $\mathrm{H}_{2} \mathrm{OCl}^{+}$(Rebenne et al., 1996). This phenomenon could be responsible for the sharp increase in atrazine removal when the current density increased from 150 to $200 \mathrm{~A} \mathrm{~m}^{-2}$, as in the latter conditions the $\mathrm{pH}$ rapidly dropped from 5.13 to 2.91 (Table S5). In a previous study Malpass et al. (2006) demonstrated a dependency of atrazine electrochemical oxidation on the presence of FAC. Moreover, the $\mathrm{pH}$ will influence the active surface sites of
MMO anodes as well as their redox properties, accelerating the direct electron transfer reactions (Rossi et al., 2009). On the other hand, only around $30-40 \%$ of $2,4-\mathrm{D}$, triclopyr and iopromide removal was observed under these conditions, while DEET could not be oxidized.

\subsection{Removal of trace organic contaminants in batch mode}

To further investigate the effect of a prolonged exposure of trace organic contaminants in ROC to the generated oxidants, batch experiments with external circulation were performed at $J=250 \mathrm{~A} \mathrm{~m}^{-2}$. Triclopyr, 2,4-D, ibuprofen, iopromide, metolachlor, phenytoin, atrazine, and DEET were also in the batch tests more persistent than the other analysed compounds (Fig. 4 and Table S6). The oxidation of all target compounds was more efficient in batch mode due to the accumulation of oxidants in the bulk liquid, and consequently more intense indirect oxidation (Figure S3). With triclopyr as exception, all persistent trace compounds were completely oxidized in batch mode after applying $1.45 \mathrm{kA} \mathrm{h} \mathrm{m}^{-3}$. Therefore, these compounds require considerably higher electrical charge supplied per anolyte unit volume and longer residence times in order for indirect oxidation to occur.

\subsection{Bioluminescence inhibition in Vibrio fischeri}

To verify the effect of electrochemical oxidation on the toxicity of ROC a number of bioluminescence assays were performed using V. fischeri. Although for specifically acting compounds the baseline toxicity is generally marginal, in a mixture of a large number of trace organic contaminants and other chemicals with a variety of specific modes of action, the baseline toxicity could dominate the overall mixture effect (Escher and Schwarzenbach, 2002). Thus, baseline toxicity provides an integrative measure of the combination of chemicals that act together in concert. The contribution of each chemical is weighted only by its hydrophobicity. In order to follow the change of baseline toxicity of the target compounds, the bioassays were performed using the samples

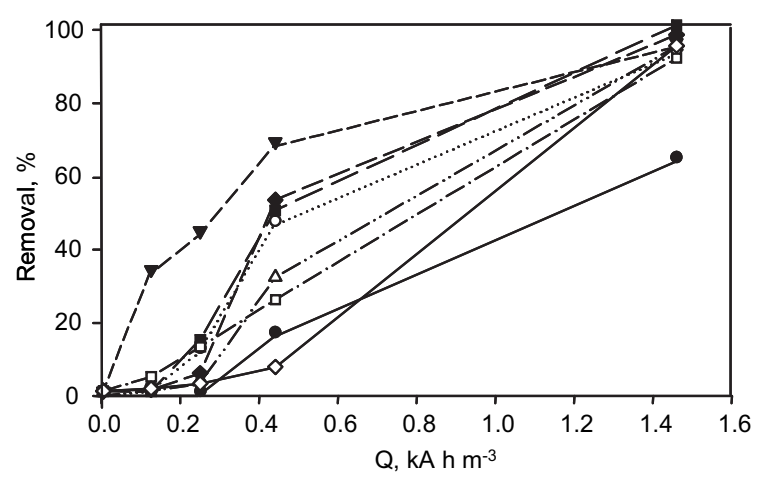

Fig. 4 - Removal of persistent target analytes vs $Q$ in anodic oxidation in batch mode at $J=250 \mathrm{~A} \mathrm{~m}^{-2}$, of ROC-1 spiked with the trace organic contaminants. - - TPR,

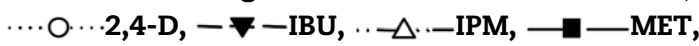
$-\cdot \square \cdot-\mathrm{PNT},-\curvearrowright-\mathrm{ATZ}, \curvearrowright$ DEET. 
enriched by the same SPE protocol as the one previously described in the section Analytical methods. The majority of matrix components such as salts, particulates, and generated oxidants were removed by the SPE sample pre-treatment. While the sample extracts of the untreated ROC-1 spiked with target analytes exhibited a TEQ value of $3.7 \pm 0.02 \mathrm{mg} \mathrm{L}^{-1}$, the toxicity of sample extracts of ROC-1 oxidized in continuous mode drastically increased with increased current density $\left(209.1 \pm 14.4 \mathrm{mg} \mathrm{L}^{-1}\right.$ at $\left.J=250 \mathrm{~A} \mathrm{~m}^{-2}\right)$ (Fig. 5a). Likewise, the toxic response of $\mathrm{V}$. fischeri increased with higher applied charge for the sample extracts of ROC-1 oxidized in batch mode (Fig. 5b). The TEQ value was increased from the initial $4.3 \pm 0.1 \mathrm{mg} \mathrm{L}^{-1}$ to $151.0 \pm 4.9 \mathrm{mg} \mathrm{L}^{-1}$ for ROC-1 oxidized in the batch reactor after applying $1.45 \mathrm{kA} \mathrm{h} \mathrm{m}^{-3}$. Although the relative increase in aromaticity (i.e. $\mathrm{SUVA}_{254}$ ) in batch oxidation suggested a higher accumulation of substituted aromatic intermediates than in the continuous mode, toxic oxidation products were formed in both reactors. It is important to note that the bioassay with V. fischeri cannot distinguish between the effects of the SPE enriched trace organic pollutants and the co-extracted organic matter. The hydrophobic (i.e. peptides and protein fragments) and/or aromatic fraction of the organic matter (fulvic- and humic-like substances) contributed to the
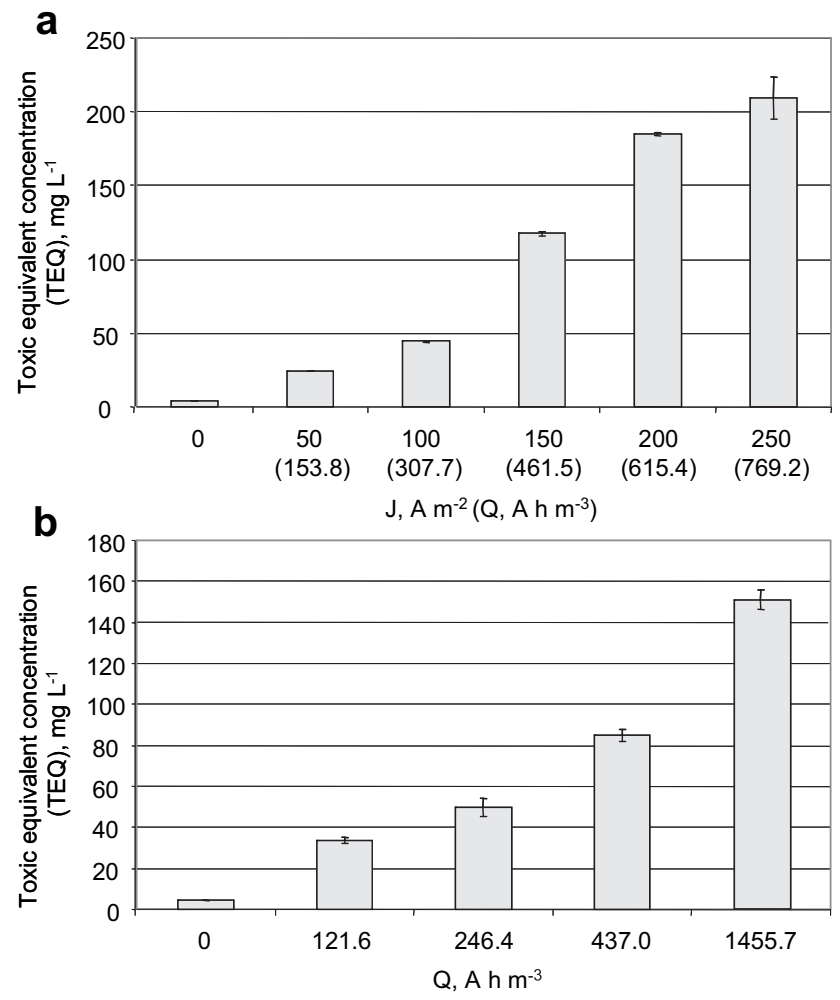

Fig. 5 - Bioluminiscence inhibition of ROC-1 spiked with target contaminants on Vibrio fischeri at $30 \mathrm{~min}$ expressed as baseline - Toxic Equivalent Concentration (TEQ) in $\mathrm{mg} \mathrm{L}^{-1}$ in: a) continuous experiment conducted at $\mathrm{J}=50$, 100, 150, 200 and $250 \mathrm{~A} \mathrm{~m}^{-2}$, b) batch experiment conducted at $J=250 \mathrm{~A} \mathrm{~m}^{-2}$. Each replicate of the sample was tested in duplicates, at eight different concentrations. Results are expressed as average of duplicates \pm standard deviation. observed increase in the toxicity, as this fraction was probably well retained on the SPE cartridge. Nevertheless, TEQ values determined for the ROC oxidized in batch and continuous mode are significantly higher than the values that could be expected owing to any potential by-products of the selected micropollutants.

\section{Conclusions}

Electrochemical oxidation at various current densities was investigated for the treatment of a reverse osmosis concentrate spiked with a mixture of pharmaceuticals and pesticides. The removal of DOC depended on the accumulation of oxidants in the bulk liquid. Based on the changes in specific aromaticity, expressed as $\mathrm{SUVA}_{254}$, it appears that the formation of chloro-, bromo- and hydroxyl-substituted aromatic intermediates was enhanced due to the prolonged indirect oxidation. Furthermore, the employed $\mathrm{Ti} / \mathrm{Ru}_{0.7} \mathrm{Ir}_{0.3} \mathrm{O}_{2}$ electrode was capable of oxidizing most of the selected pharmaceuticals and pesticides, while the most persistent compounds had electrophilic substituents at the aromatic ring (2,4-D, atrazine, triclopyr, iopromide), or an aromatic ring insufficiently activated towards nucleophilic attack (ibuprofen, phenytoin, metolachlor, DEET). Nevertheless, the results of the bioluminescence bioassay imply the formation of toxic by-products during both continuous and batch electrochemical oxidation of ROC. Although the contribution of by-products of the investigated pharmaceuticals and pesticides, and compounds formed by oxidation of other organic matter (e.g. fulvic- and humic-like substances) to the measured toxicity is uncertain, participation of oxidants such as active chlorine and bromine in indirect oxidation will likely cause transformation of organic compounds to their halogenated derivatives. This may represent an insurmountable barrier to the environmental applications of $\mathrm{RuO}_{2} / \mathrm{IrO}_{2}$-coated Ti electrodes as such byproducts could be persistent and/or require extreme treatment conditions (i.e. very high electrical charges applied). We are currently investigating downstream treatment options.

\section{Acknowledgements}

This research was supported by the Australian Research Council (grants LP0989159 and DP0985317), Veolia Water Australia, Water Secure, Magneto Special Anodes and The Urban Water Security Research Alliance. The authors would like to thank to Dr Miroslava Macova and Prof Beate Escher from National Research Centre for Environmental Toxicology, The University of Queensland, for performing the Microtox bioassays. We would also like to thank Mr Pieter Hack (Magneto Special Anodes) and Mr Yvan Poussade (Veolia Water Australia) for valuable comments.

\section{Appendix. Supplementary data}

Supplementary data related to this article can be found online at: doi:10.1016/j.watres.2010.11.035. 


\section{R E F E R E N C E S}

Acero, J.L., Benitez, F.J., Real, F.J., Gonzalez, M., 2008. Chlorination of organophosphorus pesticides in natural waters. J. Hazard. Mater 153, 320-328.

APHA 409E, 1975. Standard Methods for the Examination of Water and Wastewater. American Water Works Association (AWWA), Washington, DC.

APHA 5310B, 1998. Standard Methods for the Examination of Water and Wastewater. American Water Works Association (AWWA), Washington, DC

Bedner, M., MacCrehan, W.A., 2006a. Transformation of acetaminophen by chlorination produces the toxicants 1,4benzoquinone and N-acetyl-p-benzoquinone imine. Environ. Sci. Technol. 40, 516-522.

Bedner, M., MacCrehan, W.A., 2006b. Reactions of the aminecontaining drugs fluoxetine and metoprolol during chlorination and dechlorination processes used in wastewater treatment. Chemosphere 65, 2130-2137.

Bellona, C., Drewes, J.E., 2007. Viability of a low-pressure nanofilter in treating recycled water for water reuse applications: a pilot-scale study. Water Res. 41, 3948-3958.

Bergmann, M.E.H., Koparal, A.S., 2005a. Studies on electrochemical disinfectant production using anodes containing $\mathrm{RuO}_{2}$. J. Appl. Electrochem. 35, 1321-1329.

Bolton, J.R., Bircher, K.G., Tumas, W., Tolman, C.A., 2001. Figuresof-merit for the technical development and application of advanced oxidation technologies for both electric- and solardriven systems. Pure Appl. Chem. 73, 627-637.

Carlesi Jara, C., Fino, D., Specchia, V., Saracco, G., Spinelli, P., 2007. Electrochemical removal of antibiotics from wastewaters. Appl. Catal. B. Environ. 70, 479-487.

Chamberlain, E., Adams, C., 2006. Oxidation of sulfonamides, macrolides, and carbadox with free chlorine and monochloramine. Water Res. 40, 2517-2526.

Chen, W.H., Young, T.M., 2008. NDMA formation during chlorination and chloramination of aqueous diuron solutions. Environ. Sci. Technol. 42, 1072-1077.

Dialynas, E., Mantzavinos, D., Diamadopoulos, E., 2008. Advanced treatment of the reverse osmosis concentrate produced during reclamation of municipal wastewater. Water Res. 42, 4603-4608.

Dodd, M.C., Shah, A.D., von Gunten, U., Huang, C.H., 2005. Interactions of fluoroquinolone antibacterial agents with aqueous chlorine: reaction kinetics, mechanisms, and transformation pathways. Environ. Sci. Technol. 39, 7065-7076.

Escher, B.I., Schwarzenbach, R.P., 2002. Mechanistic studies on baseline toxicity and uncoupling of organic compounds as a basis for modeling effective membrane concentrations in aquatic organisms. Aquat. Sci. 64, 20-35.

Escher, B.I., Bramaz, N., Mueller, J.F., Quayle, P., Rutishauser, S., Vermeirssen, E.L.M., 2008. Toxic equivalent concentrations (TEQs) for baseline toxicity and specific modes of action as a tool to improve interpretation of ecotoxicity testing of environmental samples. J. Environ. Monit. 10, 612-621.

Gallard, H., Leclercq, A., Croue, J.P., 2004. Chlorination of bisphenol A: kinetics and by-products formation.

Chemosphere 56, 465-473.
Gould, J.P., Richards, J.T., 1984. The kinetics and products of the chlorination of caffeine in aqueous solution. Water Res. 18, 1001-1009.

Huber, M.M., Korhonen, S., Ternes, T.A., von Gunten, U., 2005. Oxidation of pharmaceuticals during water treatment with chlorine dioxide. Water Res. 39, 3607-3617.

Malpass, G.R., Miwa, D.W., Machado, S.A., Olivi, P., Motheo, A.J., 2006. Oxidation of the pesticide atrazine at DSA ${ }^{\circledR}$ electrodes. J. Hazard. Mater 137, 565-572.

Nurmi, J.T., Tratnyek, P.G., 2002. Electrochemical properties of natural organic matter (NOM), fractions of NOM, and model biogeochemical electron shuttles. Environ. Sci. Technol. 36, $617-624$.

Panizza, M., 2010. In: Comninellis, C., Guohua, C. (Eds.), Importance of Electrode Material in the Electrochemical Treatment of Wastewater Containing Organic Pollutants in Electrochemistry for the Environment. Springer New York, New York.

Papastefanakis, N., Mantzavinos, D., Katsaounis, A., 2010. DSA electrochemical treatment of olive mill wastewater on $\mathrm{Ti} /$ $\mathrm{RuO}_{2}$ anode. J. Appl. Electrochem. 40, 729-737.

Perez, G., Fernandez-Alba, A.R., Urtiaga, A.M., Ortiz, I., 2010. Electro-oxidation of reverse osmosis concentrates generated in tertiary treatment. Water Res. 44, 2763-2772.

Radjenovic, J., Petrovic, M., Ventura, F., Barcelo, D., 2008. Rejection of pharmaceuticals in nanofiltration and reverse osmosis membrane drinking water treatment. Water Res. 42, 3601-3610.

Rajkumar, D., Kim, J.G., Palanivelu, K., 2005. Indirect electrochemical oxidation of phenol in the presence of chloride for wastewater treatment. Chem. Eng. Technol. 28, 98-105.

Rebenne, L.M., Gonzalez, A.G., Olson, T.M., 1996. Aqueous chlorination kinetics and mechanism of substituted dihydroxybenzenes. Environ. Sci. Technol. 30, 2235-2242.

Rossi, A., Alves, V.A., Da Silva, L.A., Oliveira, M.A., Assis, D.O.S., Santos, F.A., De Miranda, R.R.S., 2009. Electrooxidation and inhibition of the antibacterial activity of oxytetracycline hydrochloride using a $\mathrm{RuO}_{2}$ electrode. J. Appl. Electrochem. 39, 329-337.

Snyder, S.A., Adham, S., Redding, A.M., Cannon, F.S., DeCarolis, J., Oppenheimer, J., Wert, E.C., Yoon, Y., 2007. Role of membranes and activated carbon in the removal of endocrine disruptors and pharmaceuticals. Desalination 202, 156-181.

Van Hege, K., Verhaege, M., Verstraete, W., 2002. Indirect electrochemical oxidation of reverse osmosis membrane concentrates at boron-doped diamond electrodes. Electrochem. Commun. 4, 296-300.

Westerhoff, P., Moon, H., Minakata, D., Crittenden, J., 2009. Oxidation of organics in retentates from reverse osmosis wastewater reuse facilities. Water Res. 43, 3992-3998.

Westerhoff, P., Yoon, Y., Snyder, S., Wert, E., 2005. Fate of endocrine-disruptor, pharmaceutical, and personal care product chemicals during simulated drinking water treatment processes. Environ. Sci. Technol. 39, 6649-6663.

Wulfeck-Kleier, K.A., Ybarra, M.D., Speth, T.F., Magnuson, M.L., 2010. Factors affecting atrazine concentration and quantitative determination in chlorinated water. J. Chromatogr. A. 1217, 676-682. 